\title{
An activated carbon fiber cathode for the degradation of glyphosate in aqueous solutions by the Electro-Fenton mode: Optimal operational conditions and the deposition of iron on cathode on electrode reusability
}

\author{
Huachun Lan ${ }^{a}$, Wenjing He ${ }^{a}$, Aimin Wang ${ }^{c}$, Ruiping Liu ${ }^{\text {a, e, * }}$, Huijuan Liu ${ }^{\text {b, e }}$, \\ Jiuhui Qu ${ }^{\text {a, e }}$, C.P. Huang ${ }^{\text {d, ** }}$ \\ ${ }^{a}$ Key Laboratory of Drinking Water Science and Technology, Research Center for Eco-Environmental Sciences, Chinese Academy of Science, Beijing 100085, \\ China \\ b State Key Laboratory of Environmental Aquatic Chemistry, Research Center for Eco-Environmental Sciences, Chinese Academy of Sciences, Beijing 100085, \\ China \\ ${ }^{c}$ Department of Municipal \& Environmental Engineering, School of Civil Engineering, Beijing Jiaotong University, China \\ ${ }^{d}$ Department of Civil and Environmental Engineering, University of Delaware, 352 Du Pont Hall, Newark, DE 19716, USA \\ e University of Chinese Academy of Sciences, Beijing 100049, China
}

\section{A R T I C L E I N F O}

\section{Article history:}

Received 14 July 2016

Received in revised form

10 September 2016

Accepted 19 September 2016

Available online 20 September 2016

\section{Keywords:}

Electro-Fenton

Glyphosate

Activated carbon fiber (ACF)

Electrode reusability

\begin{abstract}
A B S T R A C T
An activated carbon fiber (ACF) cathode was fabricated and used to treat glyphosate containing wastewater by the Electro-Fenton (EF) process. The results showed that glyphosate was rapidly and efficiently degraded and the $\mathrm{BOD}_{5} / \mathrm{COD}$ ratio was increased to $>0.3$ implying the feasibility of subsequent treatment of the treated wastewater by biological methods. The results of ion chromatography and HPLC measurements indicated that glyphosate was completely decomposed. Effective $\cdot \mathrm{OH}$ generation and rapid recycling/recovery of the $\mathrm{Fe}^{2+}$ ions at the cathode were responsible primarily for the high performance of the ACF-EF process. Factors such as inlet oxygen gas flow rate, $\mathrm{Fe}^{2+}$ dosage, initial glyphosate concentration, applied current intensity, and solution $\mathrm{pH}$ that may affect the efficiency of the ACF-EF process were further studied and the optimum operation condition was established. Results of SEM/EDX, BET and XPS analysis showed the deposition of highly dispersed fine $\mathrm{Fe}_{2} \mathrm{O}_{3}$ particles on the ACF surface during the $\mathrm{EF}$ reaction. The possibility of using the $\mathrm{Fe}_{2} \mathrm{O}_{3}-\mathrm{ACF}$ as iron source in the EF process was assessed. Results showed that the $\mathrm{Fe}_{2} \mathrm{O}_{3}$ - ACF electrode was effective in degrading glyphosate in the EF process. The deposition of $\mathrm{Fe}_{2} \mathrm{O}_{3}$ particles on the ACF electrode had no adverse effect on the reusability of the ACF cathode.
\end{abstract}

() 2016 Published by Elsevier Ltd.

\section{Introduction}

Glyphosate is the activate ingredient of Roundup ${ }^{\mathrm{TM}}$, marketed as a non-selective, post-emergence, broad-spectrum organophosphate herbicides of wide global agricultural and non-agricultural uses (Neto and de Andrade, 2009; Manassero et al., 2010; Zhang et al., 2011). The US Environmental Protection Agency (US EPA)

\footnotetext{
* Corresponding author. Key Laboratory of Drinking Water Science and Technology, Research Center for Eco-Environmental Sciences, Chinese Academy of Science, Beijing 100085, China.

** Corresponding author.

E-mail addresses: liuruiping@rcees.ac.cn (R. Liu), huang@udel.edu (C.P. Huang)
}

has classified glyphosate as an "extremely persistent" chemical and has established a maximum glyphosate concentration in sweetwater of $0.28 \mathrm{mg} / \mathrm{L}$ (Neto and de Andrade, 2009). It has been reported that only about $0.1 \%$ of the chemical applied in agriculture practice reaches the targets that most of the chemical escapes to the environment (Pimentel, 1995). Since the half-life of glyphosate is about 7-70 days (Frontera et al., 2011), its impact on the environment is moderately significant. Furthermore, improper disposal of glyphosate containing waste can lead to the contamination of soil, groundwater and surface water.

Several conventional methods such as adsorption (Hu et al., 2011; Ren et al., 2014), membrane filtration (Speth, 1993), biological and chemical treatments (Jardim et al., 1997), have been used to 
treat glyphosate containing wastewater. The effectiveness of the above methods is varying. Adsorption and filtration do not transform the chemical nor reduce its toxicity that post-treatment may be needed. Conventional biological processes usually require a long residence time (Zhang et al., 2011). Hence, chemical treatment, especially advanced oxidation process (AOP) has been received great attention in the last decade and electrochemical AOP has become a promising technology due to its simplicity and effectiveness in treating a wide variety of hazardous organic chemicals. There are studies on the electrochemical oxidation of glyphosate using different anodes, such as $\mathrm{RuO}_{2}-\mathrm{IrO}_{2}$ dimensionally stable anode (DSA) (Neto and de Andrade, 2009) and boron doped diamond (BDD) anode (Rubí-Juárez et al., 2016). Electrochemical mineralization of herbicide can occur through direct withdrawing of electron or indirect generation of oxidation species such as hydroxyl radicals, peroxocarbonate, peroxosulfate and hypochlorite dependent on the type of supporting electrolyte. The electrogenerated oxidants are mostly responsible of herbicide degradation and achieve a complete mineralization of glyphosate. Heterogeneous photocatalysis, using $\mathrm{UV}-\mathrm{TiO}_{2}$ (Echavia et al., 2009), titania nanotubes (Zhang et al., 2012), and mesoporous graphite-like carbon supporting $\mathrm{SnO}_{2}$ (Chen et al., 2015) as photocatalysts, have also showed promising potential for the degradation of glyphosate.

Electro-Fenton process, as an advanced oxidation process, has been used to degrade toxic and refractory organic pollutants based on the incipiently electro-generated $\mathrm{H}_{2} \mathrm{O}_{2}$ from the two-electron reduction of $\mathrm{O}_{2}$ on the cathode and ferrous ions in acidic aqueous medium (eq. (1)-(3)) (Labiadh et al., 2015; Mousset et al., 2016).

$\mathrm{O}_{2}+2 \mathrm{H}^{+}+2 \mathrm{e}^{-} \rightarrow \mathrm{H}_{2} \mathrm{O}_{2} ; \quad \mathrm{E}^{0}=0.69 \mathrm{~V} / \mathrm{NHE}$

$\mathrm{Fe}^{2+}+\mathrm{H}_{2} \mathrm{O}_{2}+\mathrm{H}^{+} \rightarrow \mathrm{Fe}^{3+}+\mathrm{H}_{2} \mathrm{O}+\bullet{ }^{\bullet} \mathrm{OH} ; \mathrm{k}=63 \mathrm{~L} \mathrm{~mol}^{-1} \mathrm{~s}^{-1}$

$\mathrm{Fe}^{3+}+\mathrm{e}^{-} \rightarrow \mathrm{Fe}^{2+} ; \mathrm{E}^{0}=0.77 \mathrm{~V} / \mathrm{NHE}$

Boron-doped diamond electrode (BDD), graphite or carbonPTFE, most often used cathode (Do and Chen, 1993; Harrington and Pletcher, 1999; Brillas et al., 2004), is too expensive for large scale application. Recently, three-dimensional (3D) carbon electrode, namely, activated carbon fiber (ACF), has been reported to exhibit excellent performance in cathodic oxidation of hazardous chemicals (Wang et al., 2010). However, the following questions remain unanswered regarding the feasibility of the ACF-based EF technology: Can one reuse the ACF electrode? What is the effect of iron deposition on the ACF surface on the performance of the ACF electrode? Can $\mathrm{Fe}^{2+}$ be regenerated and recycled in situ and (vis a viz. eq. (2) and eq. (3)) at the cathode surface?

In order to answer the above questions, this research was to evaluate the efficiency of the degradation of hazardous chemicals by electro-Fenton (EF) process using ACF as cathode exemplified by glyphosate. Major factors such as inlet gas, $\mathrm{pH}$, applied current, $\mathrm{Fe}^{2+}$, and glyphosate concentration that may affect the performance of the ACF-EF process and the role of iron chemistry, i.e., $\mathrm{Fe}^{2+}$ and $\mathrm{Fe}^{3+}$, were explored. Additionally, the biodegradability of ACF-EF treated glyphosate was characterized in terms of change in $\mathrm{BOD}_{5} / \mathrm{COD}$ ratio. Finally, the optimum reaction condition for the ACF-EF degradation of glyphosate was established. Finally, the effect of iron oxide deposition on the ACF surface and its effect on the reusability of the ACF electrode for continuing degradation of glyphosate were also investigated.

\section{Materials and methods}

\subsection{Materials and reagents}

Glyphosate (purity 99.6\%) was purchased from Sigma Company. Iron (II) sulfate heptahydrate (99\%, Wako) and sodium sulfate (anhydrous, 99\%, Wako) were used as supporting electrolyte. High purity nitrogen and oxygen gas, and compressed air were purchased from Beijing Feda Hight-Tech Gas Co., Ltd and used directly. All of other reagents were of analytic grade. All solutions were prepared with ultrapure water ( $\geq 18 \mathrm{M} \Omega$, Milli-Q, Millipore).

\subsection{Equipment and procedures}

Fig. 1 shows the sketch of the 400-mL undivided cell with twoelectrode and a magnetic stirring bar. The anode was a $6.5 \mathrm{~cm} \times 7.0 \mathrm{~cm} \mathrm{RuO} 2 / \mathrm{Ti}$ mesh and the cathode was ACF felt coated $\mathrm{RuO}_{2} / \mathrm{Ti}$ mesh with the same area as the anode. The DC power was provided by a power supply (DH1718E-4, Dahua Instrument Co., Beijing). The synthetic wastewater was consisted of a predetermined amount of glyphosate in $0.1-\mathrm{M} \mathrm{Na} \mathrm{NO}_{4}$ supporting electrolyte. Unless otherwise specified, pure $\mathrm{O}_{2}$ was fed into the solution at $100 \mathrm{~mL} / \mathrm{min}$. At given times, samples were taken and filtrated through $0.45-\mu \mathrm{m}$ membrane for the analysis of residual glyphosate. The $\mathrm{pH}$ of the reaction solution was adjusted by $0.1 \mathrm{M}$ $\mathrm{NaOH}$ and $\mathrm{H}_{2} \mathrm{SO}_{4}$ solutions.

\subsection{Characterization of the electrode}

The electrode was characterized by scanning electron microscopy (SEM, Hitachi S-3000N), X-ray photoelectron spectroscopy (XPS), energy dispersive X-ray (EDX) analysis, and electrochemical workstation (CHI 660E, Chenhua, Shanghai). Specific surface area was determined by nitrogen adsorption/desorption using a Micromeritics ASAP2000 analyzer (Micromeritics Co., USA). The Xray photoelectron spectroscopy (XPS) data were taken on an AXISUltra instrument from Kratos using monochromatic $\mathrm{Al} \mathrm{K} \alpha$ radiation (225 W, $15 \mathrm{~mA}, 15 \mathrm{kV}$ ) and low-energy electron flooding for charge compensation. To compensate for surface charge effects, the binding energies were calibrated using the $\mathrm{C} 1 \mathrm{~s}$ hydrocarbon peak at $284.80 \mathrm{eV}$.

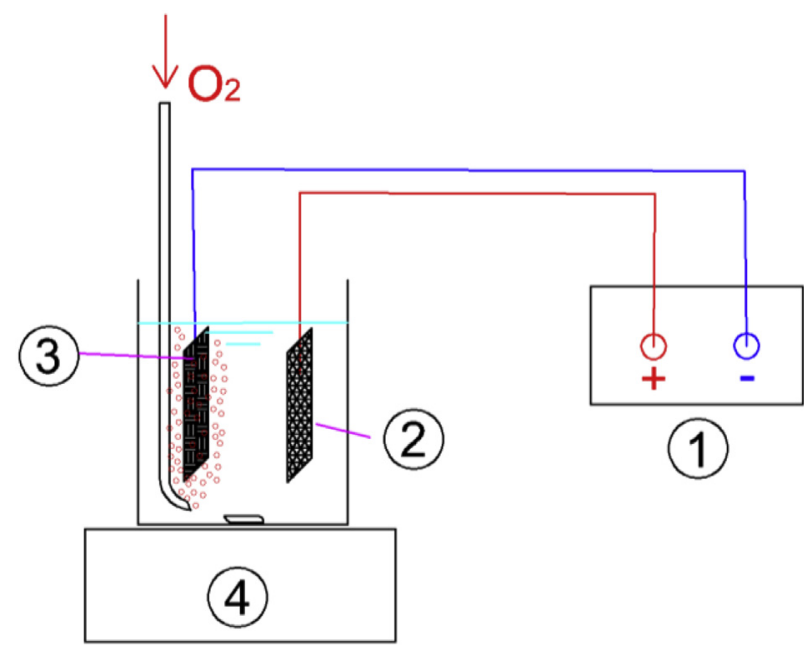

Fig. 1. Experimental setup of the electrochemical reactor: (1) DC power supply, (2) $\mathrm{RuO}_{2} / \mathrm{Ti}$ anode, (3) ACF felt cathode, and (4) Magnetic stirrer. 


\subsection{Analytical chemical method}

Glyphosate was analyzed by ion chromatography with an Ion PacAG19-HC $(4 \mathrm{~mm} \times 250 \mathrm{~mm})$ guard column, an AS19A-HC $(4 \mathrm{~mm} \times 50 \mathrm{~mm})$ separating column, and an ion selfregenerating suppressor (Alltech DS-Plus). $\mathrm{KOH}$ solution $(30 \mathrm{mM}$ ) was used as eluent at a flow rate of $1.2 \mathrm{~mL} / \mathrm{min}$ (Lan et al., 2013). The injection volume was $25 \mu \mathrm{L}$ with a suppress current of $90 \mathrm{~mA}$. The concentration of intermediates was analyzed using highperformance liquid chromatography (1200 series; Agilent, Santa Clara, CA) with a HPLC organic acid analysis column (Aminex HPX$87 \mathrm{H}$ Ion Exclusion Column, $7.8 \mathrm{~mm} \times 300 \mathrm{~mm}$ ). COD, BOD 5 and iron ion concentration were measured according to the according to Standard Methods (A.P.H.A, 1998). The total organic carbon (TOC) content of the solution was analyzed using a Phoenix 8000 TOC analyzer. Determination of hydroxyl radicals and $\mathrm{H}_{2} \mathrm{O}_{2}$ was performed with a photometric method (Babbs and Gale, 1987; Steiner and Babbs, 1990; Klassen et al., 1994): methanesulfinic acid (MSA) generated from the reaction of $\cdot \mathrm{OH}$ and DMSO can then react with fast blue BB salt to form a yellow diazosulfone compound. Hence, - $\mathrm{OH}$ concentration was measured quantitatively by determining the maximum absorbance wavelength at $425 \mathrm{~nm}$. Hydrogen peroxide was determined by the iodide method as follows. Aliquots $(1.5 \mathrm{~mL})$ of samples were added in $10 \mathrm{~mm}$ quartz cuvettes, and $0.75 \mathrm{~mL}$ $0.1 \mathrm{M}$ potassium biphthalate and $0.75 \mathrm{~mL}$ of iodide reagent $(0.4 \mathrm{M}$ potassium iodide, $0.06 \mathrm{M} \mathrm{NaOH}, \approx 10^{-4} \mathrm{M}$ ammonium molybdate) were then added. The absorbance of the treated solution was measured with a UV-visible spectrophotometer (Hitachi 3010) at $\lambda=352 \mathrm{~nm} \varepsilon=26,400 \mathrm{M}^{-1} \mathrm{~cm}^{-1}$ ). While the $\mathrm{Fe}^{2+}$ and $\mathrm{Fe}^{3+}$ concentration in solution was measured by determination of the absorbance at $514 \mathrm{~nm}$ of the complex of $\mathrm{Fe}^{2+}$ and 1,10Phenanthroline. The $\mathrm{Fe}^{3+}$ amount was calculated as follows: the total amount of iron $\left(\mathrm{Fe}^{2+}\right.$ and $\left.\mathrm{Fe}^{3+}\right)$ was measured by reducing $\mathrm{Fe}^{3+}$ to $\mathrm{Fe}^{2+}$ by hydroxylamine hydrochloride; after measuring the amount of $\mathrm{Fe}^{2+}$ in solution (without $\mathrm{Fe}^{3+}$ reduction), so that $\left[\mathrm{Fe}^{3+}\right]=$ total $[\mathrm{Fe}]-\left[\mathrm{Fe}^{2+}\right]$. All of the experiments were repeated three times.

\section{Results and discussion}

\subsection{Comparative degradation of glyphosate in different EAOP processes}

Fig. 2 shows results of glyphosate degradation by (a) $\mathrm{RuO}_{2} / \mathrm{Ti}$ anodic oxidation (AO); (b) oxidation by electro-generated $\mathrm{H}_{2} \mathrm{O}_{2}$ in the absence of $\mathrm{Fe}^{2+}\left(\mathrm{AO}-\mathrm{H}_{2} \mathrm{O}_{2}\right)$; and (c) electro-Fenton process. As shown in Fig. 2A, only $10 \%$ of glyphosate was removed after $120 \mathrm{~min}$ by anodic oxidation. It could be speculated that the $\mathrm{RuO}_{2} / \mathrm{Ti}$ mesh anode had a high electrochemical activity toward oxygen evolution thereby exhibiting low chemical reactivity for glyphosate oxidation. The $\mathrm{AO}-\mathrm{H}_{2} \mathrm{O}_{2}$ system exhibited a slightly greater glyphosate oxidation at $25 \%$ (Fig. $2 \mathrm{~A} \mathrm{~b}$ ) compared to that of the $\mathrm{RuO}_{2} / \mathrm{Ti}$ electrode (Fig. $2 \mathrm{~A}$ a). In addition to direct $\mathrm{AO}$ oxidation, $\mathrm{H}_{2} \mathrm{O}_{2}$ generated at the cathode played the major role on the removal of glyphosate.

In contrast, the EF process exhibited the highest glyphosate oxidation capacity at ca. $85 \%$ after $120 \mathrm{~min}$ (Fig. 2A c). Moreover, the degradation rate of glyphosate reached $75 \%$ after $10 \mathrm{~min}$. It must be noted that the degree of glyphosate degradation was parallel to that of the formation of $\cdot \mathrm{OH}$ radical (Inset, Fig. 2A). Much more $\cdot \mathrm{OH}$ radicals was generated in the EF process than the other two systems and reached the steady state level at $30 \mathrm{~min}$, whereas the amount of $\cdot \mathrm{OH}$ generated in the $\mathrm{AO}-\mathrm{H}_{2} \mathrm{O}_{2}$ system was notably lower and there was almost no $\cdot \mathrm{OH}$ formation in the $\mathrm{AO}$ system compared to the ACF-EF system. Hence, the extent of $\cdot \mathrm{OH}$ generation facilitated glyphosate degradation in the EF process per the Haber and Weiss
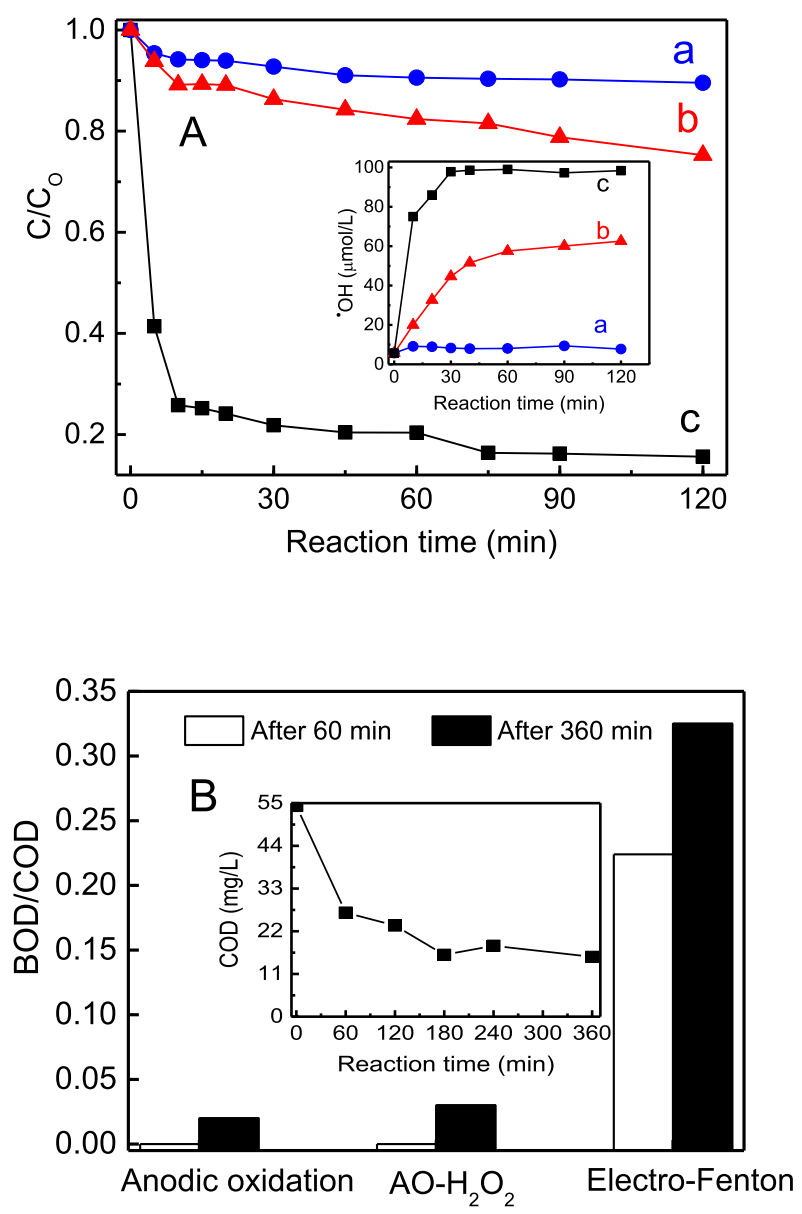

Fig. 2. Glyphosate degradation and $\bullet \mathrm{OH}$ generation (inset) at different processes: (a) AO oxidation over $\mathrm{RuO}_{2} / \mathrm{Ti}$, (b) $\mathrm{AO}-\mathrm{H}_{2} \mathrm{O}_{2}$ and (c) electro-Fenton. (B) Changes of glyphosate biodegradability in different processes and the inset is the COD removal of glyphosate solution in electro-Fenton process.

mechanism.

$\mathrm{BOD}_{5} / \mathrm{COD}$ ratio is an engineering indicator of the degree of biodegradability. It has been reported that $\mathrm{BOD}_{5} / \mathrm{COD}>0.3-0.4$ represents complete biodegradation of the organic compounds (Chamarro et al., 2001). Fig. $2 \mathrm{~B}$ shows the change in $\mathrm{BOD}_{5} / \mathrm{COD}$ ratio and thus biodegradability of glyphosate in different EAOPs. The results indicated that after 360 min $(6 \mathrm{~h}) 72 \%$ of total COD was removed (Inset, Fig. $2 \mathrm{~B}$ ), and the $\mathrm{BOD}_{5} / \mathrm{COD}$ was greater than 0.3 , which indicated that the ACF-EF treated wastewater was amenable to biological treatments.

\subsection{Parameters affecting the performance of the ACF-EF process}

Based on the above results, the ACF-EF process was proven to be the most effective method for glyphosate degradation. The parameters affecting the performance of the ACF-EF process with respect to glyphosate degradation was investigated. Firstly, the cyclic voltammetry (CV) and linear sweeping voltammetry (LSV) analysis suggested the feasibility of ACF cathode for the production of $\mathrm{H}_{2} \mathrm{O}_{2}$ through the electrochemical reduction (Fig. S1). In this experiment, different gases were introduced into the system to ensure dissolved gases saturation before reaction. Fig. 3 shows the accumulation of $\mathrm{O}_{2}, \mathrm{H}_{2} \mathrm{O}_{2}$ and the corresponding $\cdot \mathrm{OH}$ formation as a function of reaction time in the presence of different inlet gases. Results clearly indicated that $\mathrm{H}_{2} \mathrm{O}_{2}$ and $\cdot \mathrm{OH}$ increased quickly with 

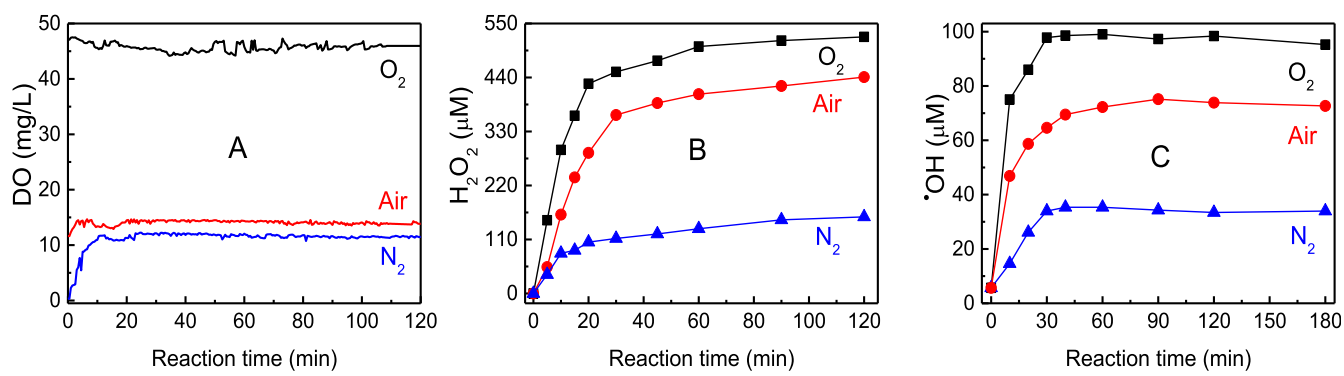

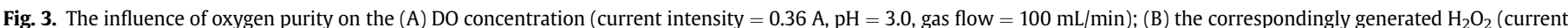

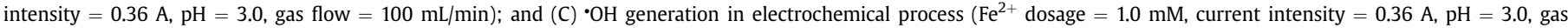
flow $=100 \mathrm{~mL} / \mathrm{min}$ )

time until a steady state was achieved and followed the order: $\mathrm{N}_{2}<$ air $<\mathrm{O}_{2}$, which was a reflection of the DO concentration in the solution. The steady-state DO concentration was measured as 12 , 14.5 and $45 \mathrm{mg} / \mathrm{L}$ when sparging with $\mathrm{N}_{2}$, air, and pure oxygen, respectively. The quick increase of DO in the $\mathrm{N}_{2}$ atmosphere after applying power supply could be attributed to the anodic oxygen evolution. Hence, unless otherwise stated, $\mathrm{O}_{2}$ was always chosen as the inlet gas in all following experiments.

The effect of $\mathrm{Fe}^{2+}$ and glyphosate concentration, applied current density, and solution $\mathrm{pH}$ on glyphosate degradation was also evaluated in terms of TOC removal by the ACF-EF process. Fig. $4 \mathrm{~A}$ shows TOC change as affected by $\mathrm{Fe}^{2+}$ dose (from 0 to $1.0 \mathrm{mM}$ ) at $\mathrm{pH} 3.0$ and current intensity of $0.36 \mathrm{~A}$ in the presence of $0.1 \mathrm{mM}$ of glyphosate after $360 \mathrm{~min}(6 \mathrm{~h})$ of treatment. The TOC removal was increased from 20 to $50 \%$ when the $\mathrm{Fe}^{2+}$ dosage was increased from 0 to $1 \mathrm{mM}$, correspondingly. The effect of the initial concentration of glyphosate on its mineralization was studied in four concentrations in the presence of $1 \mathrm{mM}$ of $\mathrm{Fe}^{2+}$ with a $\mathrm{pH}$ of 3.0 and current
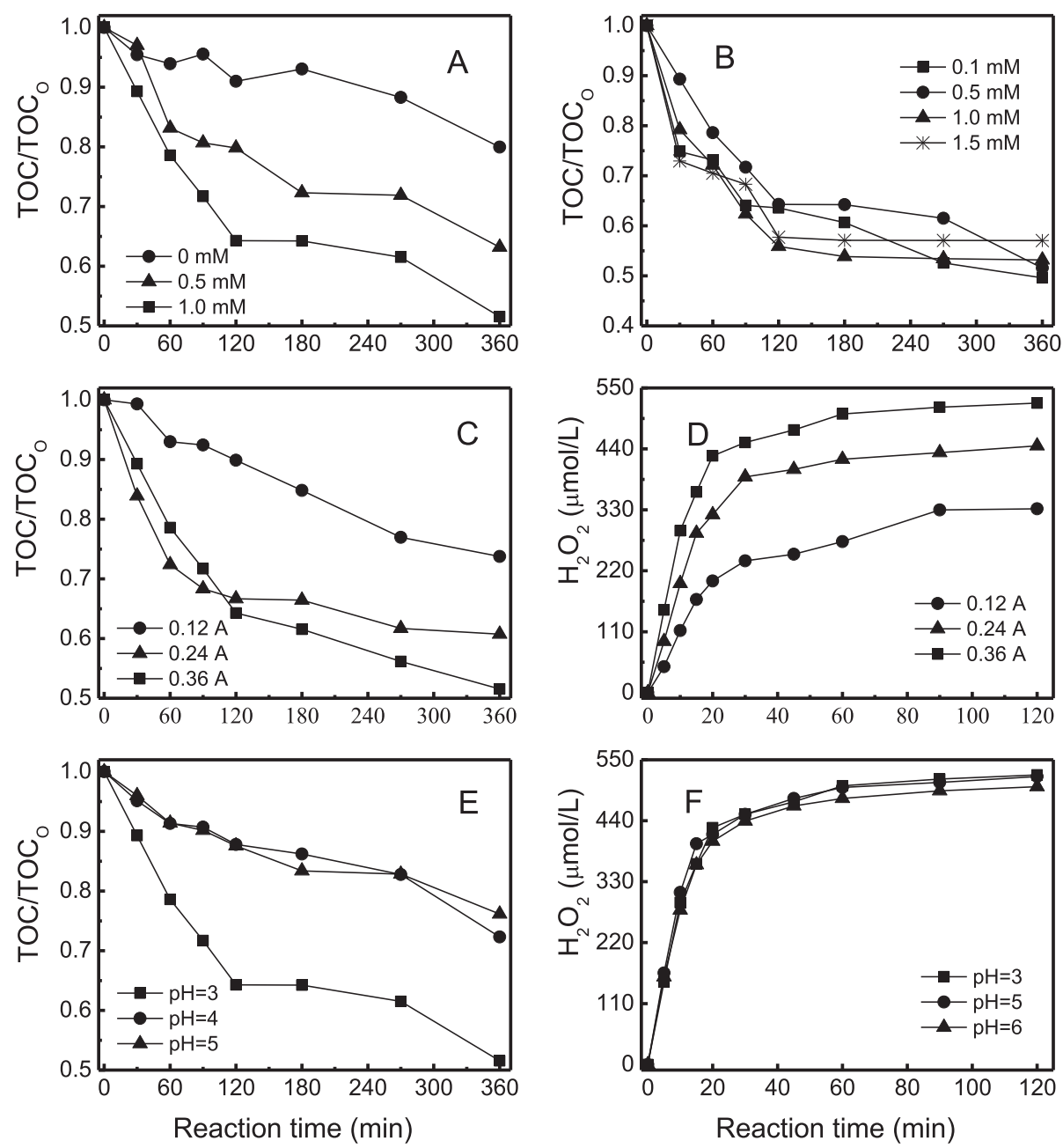

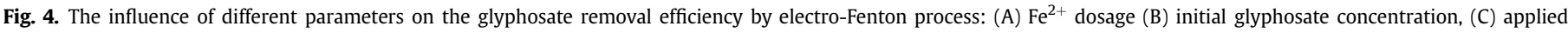
current, (E) initial solution $\mathrm{pH}$. (D) and (F) represent the $\mathrm{H}_{2} \mathrm{O}_{2}$ generation under different applied current and initial solution pH. 
intensity of $0.36 \mathrm{~A}$ (Fig. 4B). After $360 \mathrm{~min}$ ( $6 \mathrm{~h}$ ) of electrolysis, the TOC removal was $50.4,48.5,46.9$, and $43.0 \%$ at initial glyphosate concentration of $0.1,0.5,1.0$ and $1.5 \mathrm{mM}$, respectively. In general, the TOC removal was not sensitive to the initial glyphosate concentration in the range studied, presumably due to the presence of excess $\mathrm{H}_{2} \mathrm{O}_{2}$ or hydroxyl radical. The effect of applied current on TOC removal was also examined at $0.12,0.24$ and $0.36 \mathrm{~A}$ in the presence of 0.1 of $\mathrm{mM}$ glyphosate and $\mathrm{pH}$ 3.0.

As shown in Fig. 4C, 26.25, 39.26 and $48.45 \%$ of TOC was removed after $360 \mathrm{~min}(6 \mathrm{~h})$, in the presence of $0.12,0.24$ and $0.36 \mathrm{~A}$ of current intensity, respectively. It was found that increasing the current intensity in the range 0.12-0.36 A significantly enhanced the mineralization of glyphosate. The enhanced glyphosate removal by increasing the current density could be attributed to the increase in the production of $\mathrm{H}_{2} \mathrm{O}_{2}$ (Fig. 4D), subsequently, which resulted in the enhancement of $\cdot \mathrm{OH}$ generation since the production of $\cdot \mathrm{OH}$ is proportional to the $\mathrm{H}_{2} \mathrm{O}_{2}$ concentration (Qiu et al., 2015; Wang et al., 2016). A notable $\mathrm{pH}$ effect on the degradation of glyphosate was observed (Fig. 4E), reaching a maximum TOC removal of $48.45 \%$ at $\mathrm{pH} 3.0$ in $360 \mathrm{~min}(6 \mathrm{~h})$. It is noted that there was no significant difference in $\mathrm{H}_{2} \mathrm{O}_{2}$ generation within the range of solution $\mathrm{pH}$ studied (Fig. 4F). Hence, at $\mathrm{pH}>3.0$ decrease in glyphosate decomposition could be due to a weakening of the oxidation potential of $\cdot \mathrm{OH}$ and a decrease in $\mathrm{Fe}^{2+}$ concentration due to $\mathrm{pH}$-dependent $\mathrm{Fe}(\mathrm{II})$ speciation. Our result was in total agreement with those reported in the literature on the degradation of organic pollutants by electro-Fenton method. Furthermore, the optimum $\mathrm{pH}$ of 2.8 was consistent with typically reported value for maximum Fenton's reaction (Sun and Pignatello, 1993; Panizza and Cerisola, 2009). Based on the above results, the optimum reaction condition for the present ACF-EF process was: applied current intensity $=0.36 \mathrm{~A}$, pure $\mathrm{O}_{2}$ flow rate $=100 \mathrm{~mL} / \mathrm{min}$, $\left[\mathrm{Fe}^{2+}\right]=1.0 \mathrm{mM}$, [glyphosate] $=0.1 \mathrm{mM}$, and $\mathrm{pH}<3.0$.

\subsection{The mechanism on the degradation of glyphosate}

The intermediates of the degradation of glyphosate were further monitored using ion chromatography (inorganic ions) and HPLC (small molecular organic acid) (Fig. 5). Obviously, the concentration of ammonium, nitrate, and phosphate were increased with reaction time, which indicated that the primary chemical structure of glyphosate was destroyed and that ammonium was oxidized to nitrite and finally to nitrate. The nitrite was not detected in the system probably due to tits quick oxidation to nitrate by $\cdot \mathrm{OH}$. The increase in acetic acid and oxalic acid concentration during glyphosate degradation also proved the cleavage of the $\mathrm{C}-\mathrm{P}$ and

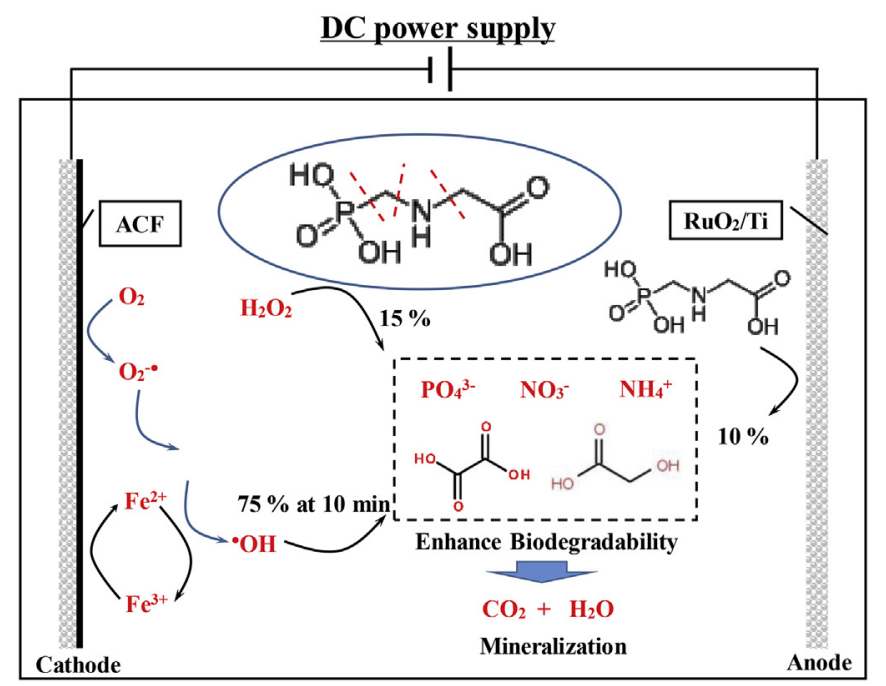

Fig. 6. The proposed reaction mechanism of glyphosate degradation in electro-Fenton process.

$\mathrm{C}-\mathrm{N}$ bond of glyphosate and subsequent generation of aliphatic acids. Based on the experimental results, the reaction mechanism of the ACF-EF process, a preliminarily proposed glyphosate degradation pathway could be proposed (Fig. 6). First, oxygen was adsorbed onto the ACF surface and $\mathrm{H}_{2} \mathrm{O}_{2}$ was then efficiently generated thorough the reduction of oxygen on cathode. Meanwhile, $\mathrm{Fe}^{2+}$ immediately and catalytically decomposed $\mathrm{H}_{2} \mathrm{O}_{2}$ to generate hydroxyl radicals presumably through the Haber-Weiss mechanism. The regeneration of $\mathrm{Fe}^{2+}$ ions could be mainly brought by a direct cathode reaction via electro-reduction of $\mathrm{Fe}^{3+}$ ions. The degradation of glyphosate started with breaking the $\mathrm{C}-\mathrm{N}$ and $\mathrm{C}-\mathrm{P}$ bond to form acetic acid and oxalic acid. Finally, most of the organic intermediates were converted to carbon dioxide and inorganic ions, respectively. For instance, the nitrogen atom was released as ammonium and nitrate ions, and the $\mathrm{P}$ atom was converted to phosphate.

\subsection{Iron deposition on ACF and its effect on electrode reusability}

In the $\mathrm{ACF}-\mathrm{EF}$ process, $\mathrm{Fe}^{3+}$ or $\mathrm{Fe}^{2+}$ ion, as Fenton or Fenton-like catalyst, was beneficial to $\cdot \mathrm{OH}$ generation. Therefore, it is justified to investigate the iron cycle further. Fig. 7A shows the change of iron ion concentration upon the addition of $\mathrm{Fe}^{2+}$ to the reaction system.
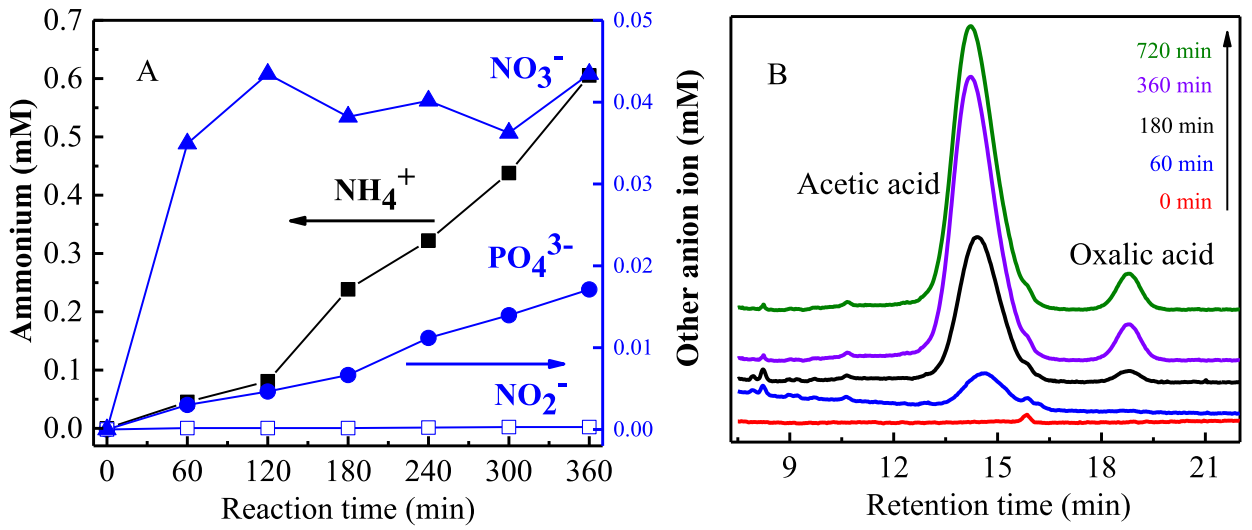

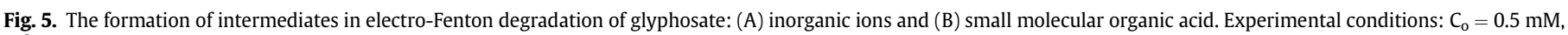
$\mathrm{Fe}^{2+}$ dosage $=1.0 \mathrm{mM}$, current intensity $=0.36 \mathrm{~A}, \mathrm{pH}=3.0$, and $\mathrm{O}_{2}=100 \mathrm{~mL} / \mathrm{min}$ ). 

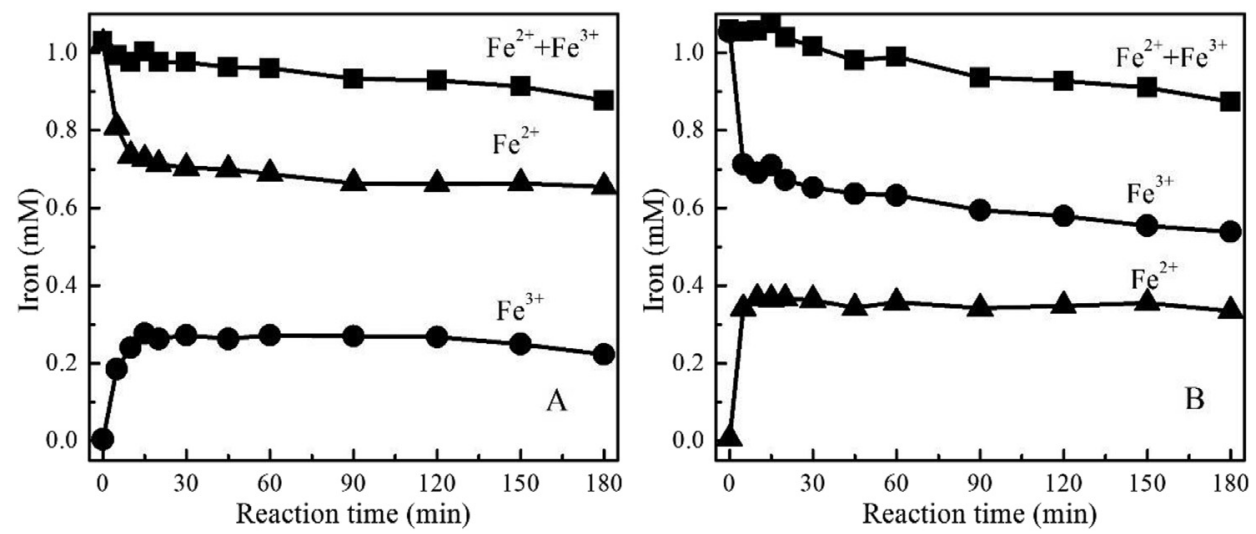

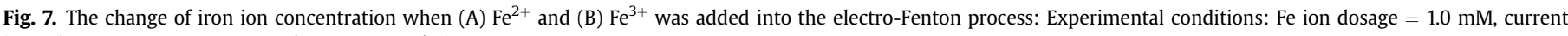
intensity $=0.36 \mathrm{~A}, \mathrm{pH}=3.0$, and $\mathrm{O}_{2}=100 \mathrm{~mL} / \mathrm{min}$.

There was a rapid decay of $\mathrm{Fe}^{2+}$ concentration and simultaneous increase in $\mathrm{Fe}^{3+}$ content. The steady state was achieved quickly in about 15 min for both $\mathrm{Fe}^{2+}$ and $\mathrm{Fe}^{3+}$, which agreed with the results of $\cdot \mathrm{OH}$ generation and glyphosate degradation (Fig. 2). On the other hand, when $\mathrm{Fe}^{3+}$ was added to the reaction system, it was also reduced quickly to $\mathrm{Fe}^{2+}$ and reached the steady state condition in about 10 min as well (Fig. 7B). Fast regeneration of $\mathrm{Fe}^{2+}$ species at the ACF electrode is essential for sustaining the oxidation capacity of the ACF-EF system, since $\mathrm{Fe}^{2+}$ ion is needed to form ${ }^{\circ} \mathrm{OH}$ per the Fenton's reaction (Sires et al., 2007; Oturan et al., 2008).

According to Fig. 7, the total amount of iron $\left(\mathrm{Fe}^{2+}\right.$ and $\left.\mathrm{Fe}^{3+}\right)$ was decreased with reaction time regardless of the form of the iron species, i.e., $\mathrm{Fe}^{2+}$ or $\mathrm{Fe}^{3+}$, added to the system, which indicated clearly that some iron oxide should be deposited onto the ACF electrode surface as verified by SEM imaging (Fig. 8A and B). As shown in Fig. 8A \& B, some white clusters appeared on the ACF surface after the electro-Fenton reaction. Based on the EDX analysis (Inset, Fig. 8A and B), iron element indeed was present on the ACF electrode surface at atomic ratio of $0.59 \%$ compared to fresh ACF after the cathodic process period.

Fig. $8 \mathrm{C}$ shows the $\mathrm{N}_{2}$ adsorption-desorption isotherms. The iron deposition did not change significantly the pore size distribution of ACF. The BET surface area of the ACF electrode before and after EF reaction was 1053 and $940 \mathrm{~m}^{2} / \mathrm{g}$, respectively. The $\mathrm{N}_{2}$ adsorptiondesorption isotherms followed type III with hysteresis loops, which implies the presence of mesoporous structure after EF
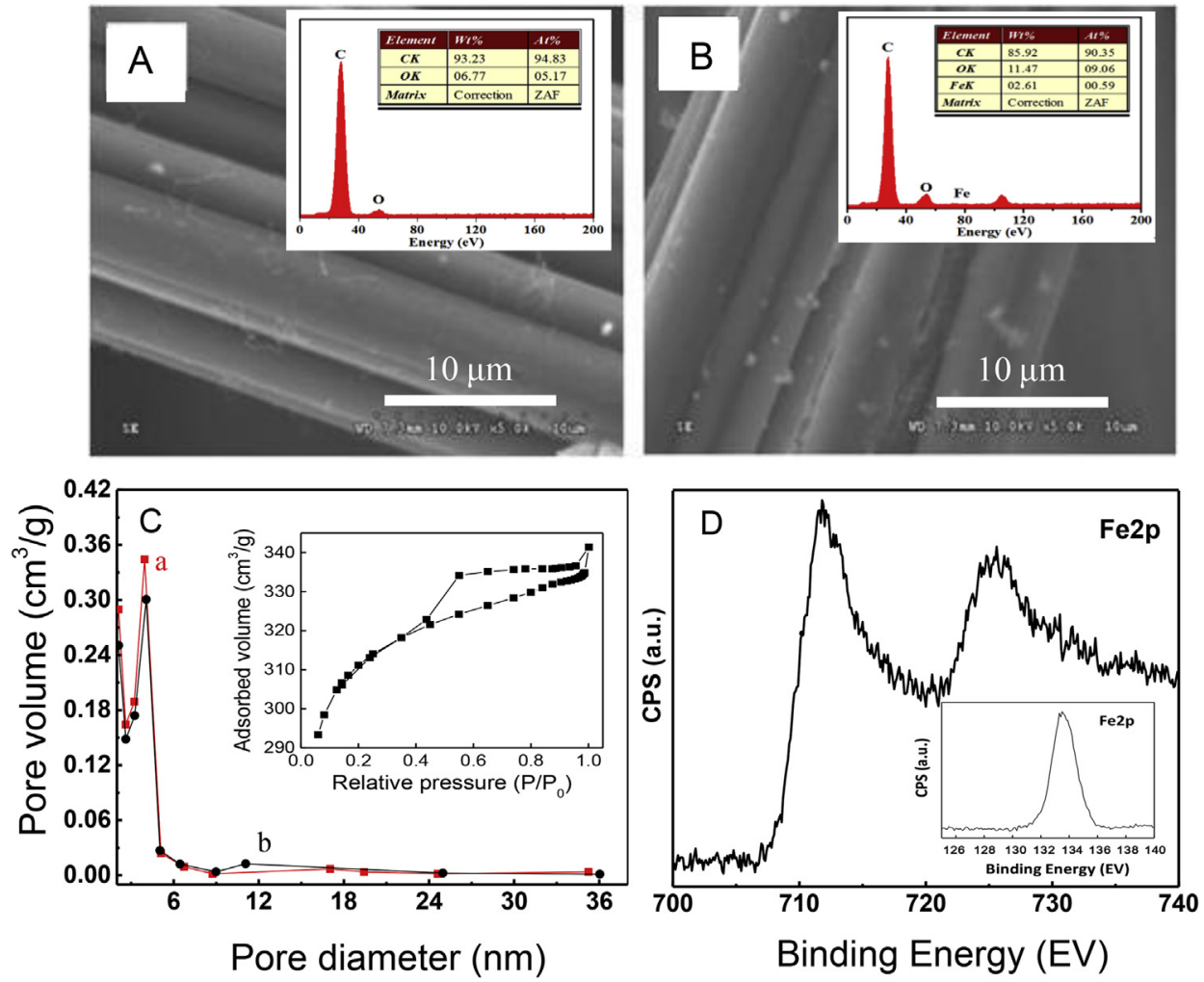

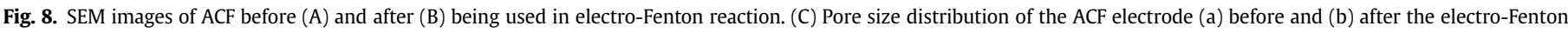
reaction. The inset shows the nitrogen adsorption-desorption isotherm of the used ACF. (D) XPS spectra of Fe $2 p$ of iron deposited on the surface of ACF 
reaction. Moreover, the XPS peaks (Fig. 8D) at 711, 719, and $725 \mathrm{eV}$ were assigned to the binding energy of Fe2p3/2, shake-up satellite $\mathrm{Fe} 2 \mathrm{p} 3 / 2$ and Fe2p1/2 (Lan et al., 2015), suggesting the existence of $\mathrm{Fe}_{2} \mathrm{O}_{3}$. The above results indicated that $\mathrm{Fe}_{2} \mathrm{O}_{3}$ with small particle size was highly dispersed on the ACF surface and that the deposition of $\mathrm{Fe}_{2} \mathrm{O}_{3}$ did not change the ACF pore structure. It is necessary to investigate the possibility of $\mathrm{Fe}_{2} \mathrm{O}_{3} / \mathrm{ACF}$ reuse in $\mathrm{EF}$ catalytic degradation of glyphosate.

Fig. 9 depicts the electro-Fenton activity of $\mathrm{Fe}_{2} \mathrm{O}_{3} / \mathrm{ACF}$ electrode (used as iron ion source) in the catalytic degradation of glyphosate. The reused operation procedure of iron oxide deposited $\mathrm{ACF}\left(\mathrm{Fe}_{2} \mathrm{O}_{3} /\right.$ $\mathrm{ACF})$ was provided as followed: after the EF process, the used ACF $\left(\mathrm{Fe}_{2} \mathrm{O}_{3} / \mathrm{ACF}\right)$ was taken out from the reaction mixture and rinsed twice with deionized water. It was then reused directly in EF process without the addition of any $\mathrm{Fe}^{2+}$ or $\mathrm{Fe}^{3+}$. The experimental conditions were as followed: $C_{0}=0.5 \mathrm{mM}$, current intensity $=0.36$ $\mathrm{A}, \mathrm{pH}=3.0$, and $\mathrm{O}_{2}=100 \mathrm{~mL} / \mathrm{min}$. The mineralization of glyphosate by the $\mathrm{Fe}_{2} \mathrm{O}_{3} / \mathrm{ACF}$ electrode was comparable with the ACF electrode (run 1) and more significant (run $2 \& 3$ ) than the $\mathrm{AO}$ and $\mathrm{AO}-\mathrm{H}_{2} \mathrm{O}_{2}$ process (inset, Fig. 9). The oxidation capacity of the $\mathrm{Fe}_{2} \mathrm{O}_{3} / \mathrm{ACF}$ electrode decreased slightly with recycle time, which was parallel to $\cdot \mathrm{OH}$ generation under same experimental conditions. Since part of iron oxides remained on the ACF surface, the high efficiency of the $\mathrm{Fe}_{2} \mathrm{O}_{3} / A C F-E F$ system could be brought by the $\mathrm{H}_{2} \mathrm{O}_{2}$ activation to generate $\cdot \mathrm{OH}$ at the iron sites on the electrode surface (Zhao et al., 2012). Dissolution of iron oxide occurred at acidic pH of 3.0, which ultimately deactivate the oxidative function of the $\mathrm{Fe}_{2} \mathrm{O}_{3} / \mathrm{ACF}$ electrode. The results in Fig. 9 indicated that the deposition of $\mathrm{Fe}_{2} \mathrm{O}_{3}$ particles on the ACF surface had almost no influence on the cycle/ reuse of $A C F$ as cathode. Dissolution of iron oxide to yield soluble iron ions from the $\mathrm{Fe}_{2} \mathrm{O}_{3} / \mathrm{ACF}$ electrode could aid in the glyphosate gradation in the $\mathrm{EF}$ process.

\section{Conclusion}

EF reaction was efficient for the degradation of glyphosate using ACF as cathode in an acidic aqueous solution. During the degradation process, the $\mathrm{C}-\mathrm{N}$ and $\mathrm{C}-\mathrm{P}$ bond were broken and acetic acid and oxalic acid were then formed. The nitrogen atom in glyphosate was released as ammonium and nitrate ions, while the

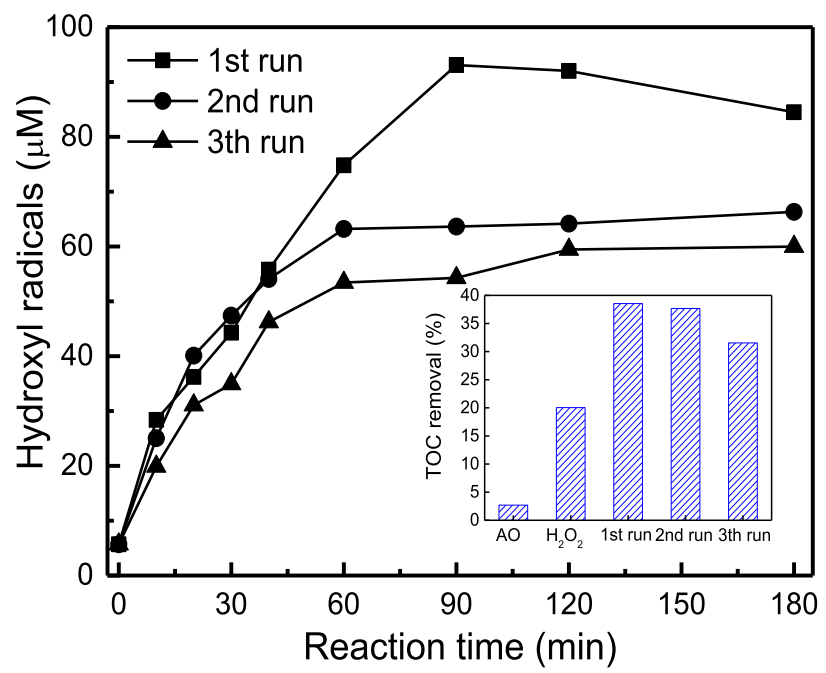

Fig. 9. $\cdot \mathrm{OH}$ generation with the repeated times when $\mathrm{Fe}_{2} \mathrm{O}_{3} / \mathrm{ACF}$ was reused in $\mathrm{EF}$ process. The inset shows the comparison of glyphosate removal efficiency by different reaction systems. Experimental conditions: $\mathrm{C}_{\mathrm{o}}=0.5 \mathrm{mM}$, current intensity $=0.36 \mathrm{~A}$, $\mathrm{pH}=3.0$, and $\mathrm{O}_{2}=100 \mathrm{~mL} / \mathrm{min}$. phosphorous atom was converted into phosphate. After reaction for $6 \mathrm{~h}$, the remaining intermediates from glyphosate degradation was biodegradable as the $\mathrm{BOD}_{5} / \mathrm{COD}$ ratio was $>0.3$. $\cdot \mathrm{OH}$ radical generated from the $\mathrm{H}_{2} \mathrm{O}_{2}$ activation by $\mathrm{Fe}^{2+}$ and the quick conversion of iron species at the cathode were responsible for the high performance of the electro-Fenton process. The optimum reaction condition for the present ACF-EF process was: [applied current] $=0.36$ $\mathrm{A}, \mathrm{O}_{2}$ flow rate $=100 \mathrm{~mL} / \mathrm{min},\left[\mathrm{Fe}^{2+}\right]=1.0 \mathrm{mM}$, and $\mathrm{pH}=3.0$. Moreover, based on the SEM/EDX, BET and XPS analysis, $\mathrm{Fe}_{2} \mathrm{O}_{3}$ in small particles was deposited and highly dispersed on the ACF surface during the EF reaction. $\mathrm{Fe}_{2} \mathrm{O}_{3} / \mathrm{ACF}$ could be used as iron source in the $\mathrm{EF}$ process for efficient degradation of glyphosate; hence the deposition of $\mathrm{Fe}_{2} \mathrm{O}_{3}$ particles on ACF surface had almost no influence on the cycle/reuse of ACF as cathode.

\section{Acknowledgements}

This work was supported by the National Natural Science Foundation of China (Nos. 51478455, 51438011, 51422813).

\section{Appendix A. Supplementary data}

Supplementary data related to this article can be found at http:// dx.doi.org/10.1016/j.watres.2016.09.036.

\section{References}

A.P.H.A, 1998. Standard Methods for the Examination of Water and Wastewater, twentieth ed. American Public Health Association, American Water Works Association, Water Environment Federation, Washington, DC.

Babbs, C.F., Gale, M.J., 1987. Colorimetric assay for methanesulfinic acid in biological samples. Anal. Biochem. 163, 67-73.

Brillas, E., Boye, B., Sires, I., Garrido, J.A., Rodriguez, R.M., Arias, C., Cabot, P.L., Comninellis, C., 2004. Electrochemical destruction of chlorophenoxy herbicides by anodic oxidation and electro-Fenton using a boron-doped diamond electrode. Electrochim. Acta 49 (25), 4487-4496.

Chamarro, E., Marco, A., Esplugas, S., 2001. Use of fenton reagent to improve organic chemical biodegradability. Water Res. 35 (4), 1047-1051.

Chen, X.J., Liu, F.L., Liu, B., Tian, L.H., Hu, W., Xia, Q.H., 2015. A novel route to graphite-like carbon supporting $\mathrm{SnO}_{2}$ with high electron transfer and photocatalytic activity. J. Hazard Mater 287, 126-132.

Do, J.S., Chen, C.P., 1993. In situ oxidative degradation of formaldehyde with electrogenerated hydrogen peroxide. J. Electrochem Soc. 140 (6), 1632-1637.

Echavia, G.R., Matzusawa, F., Negishi, N., 2009. Photocatalytic degradation of organophosphate and phosphonoglycine pesticides using $\mathrm{TiO}_{2}$ immobilized on silica gel. Chemosphere 76 (5), 595-600.

Frontera, J.L., Vatnick, I., Chaulet, A., Rodriguez, E.M., 2011. Effects of glyphosate and polyoxyethylenamine on growth and energetic reserves in the freshwater crayfish cherax quadricarinatus (Decapoda, Parastacidae). Arch. Environ. Contam. Toxicol. 61 (4), 590-598.

Harrington, T., Pletcher, D., 1999. The removal of low levels of organics from aqueous solutions using $\mathrm{Fe}(\mathrm{II})$ and hydrogen peroxide formed in situ at gas diffusion electrodes. J. Electrochem Soc. 146 (8), 2983-2989.

Hu, Y.S., Zhao, Y.Q., Sorohan, B., 2011. Removal of glyphosate from aqueous environment by adsorption using water industrial residual. Desalination 271 (1-3), $150-156$.

Jardim, W.F., Moraes, S.G., Takiyama, M.M.K., 1997. Photocatalytic degradation of aromatic chlorinated compounds using $\mathrm{TiO}_{2}$ : toxicity of intermediates. Water Res. 31 (7), 1728-1732.

Klassen, N.V., Marchington, D., McGowan, H.C.E., 1994. $\mathrm{H}_{2} \mathrm{O}_{2}$ determination by the I3- method and by $\mathrm{KMnO}_{4}$ titration. Anal. Chem. 66 (18), 2921-2925.

Labiadh, L., Oturan, M.A., Panizza, M., Ben Hamadi, N., Ammar, S., 2015. Complete removal of AHPS synthetic dye from water using new electro-fenton oxidation catalyzed by natural pyrite as heterogeneous catalyst. J. Hazard Mater 297, 34-41.

Lan, H.C., Jiao, Z.F., Zhao, X., He, W.J., Wang, A.M., Liu, H.J., Liu, R.P., Qu, J.H., 2013. Removal of glyphosate from water by electrochemically assisted $\mathrm{MnO}_{2}$ oxidation process. Sep. Purif. Technol. 117, 30-34.

Lan, H.C., Wang, A.M., Liu, R.P., Liu, H.J., Qu, J.H., 2015. Heterogeneous photo-Fenton degradation of acid red $\mathrm{B}$ over $\mathrm{Fe}_{2} \mathrm{O}_{3}$ supported on activated carbon fiber. J. Hazard Mater 285, 167-172.

Manassero, A., Passalia, C., Negro, A.C., Cassano, A.E., Zalazar, C.S., 2010. Glyphosate degradation in water employing the $\mathrm{H}_{2} \mathrm{O}_{2}$ /UVC process. Water Res. 44 (13), 3875-3882.

Mousset, E., Frunzo, L., Esposito, G., van Hullebusch, E.D., Oturan, N., Oturan, M.A., 2016. A complete phenol oxidation pathway obtained during electro-Fenton 
treatment and validated by a kinetic model study. Appl. Catal. B Environ. 180, 189-198.

Neto, S.A., de Andrade, A.R., 2009. Electrooxidation of glyphosate herbicide at different DSA ${ }^{\circledR}$ compositions: $\mathrm{pH}$, concentration and supporting electrolyte effect. Electrochim. Acta 54 (7), 2039-2045.

Oturan, M.A., Guivarch, E., Oturan, N., Sires, I., 2008. Oxidation pathways of malachite green by $\mathrm{Fe}^{3+}$-catalyzed electro-Fenton process. Appl. Catal. B Environ. 82 $(3-4), 244-254$.

Panizza, M., Cerisola, G., 2009. Electro-Fenton degradation of synthetic dyes. Water Res. 43 (2), 339-344.

Pimentel, D., 1995. Amounts of pesticides reaching target pests: Environmental impacts and ethics. J. Agric. Environ. Ethics 8 (1), 17-29.

Qiu, S., He, D., Ma, J.X., Liu, T.X., Waite, T.D., 2015. Kinetic modeling of the electrofenton process: quantification of reactive oxygen species generation. Electrochim. Acta 176, 51-58.

Ren, Z., Dong, Y.H., Liu, Y., 2014. Enhanced glyphosate removal by montmorillonite in the presence of Fe(III). Ind. Eng. Chem. Res. 53 (37), 14485-14492.

Rubí-Juárez, H., Cotillas, S., Sáez, C., Cañizares, P., Barrera-Díaz, C., Rodrigo, M.A., 2016. Removal of herbicide glyphosate by conductive-diamond electrochemical oxidation. Appl. Catal. B Environ. 188, 305-312.

Sires, I., Garrido, J.A., Rodriguez, R.M., Brillas, E., Oturan, N., Oturan, M.A., 2007. Catalytic behavior of the $\mathrm{Fe}^{3+} / \mathrm{Fe}^{2+}$ system in the electro-Fenton degradation of the antimicrobial chlorophene. Appl. Catal. B Environ. 72 (3-4), 382-394.
Speth, T.F., 1993. Glyphosate removal from drinking water. J. Environ. Eng. 119 (6) 1139-1157.

Steiner, M.G., Babbs, C.F., 1990. Quantitation of the hydroxyl radical by reaction with dimethyl sulfoxide. Arch. Biochem. Biophys. 278 (2), 478-481.

Sun, Y.F., Pignatello, J.J., 1993. Photochemical reactions involved in the total mineralization of $2,4-\mathrm{D}$ by iron(3+)/hydrogen peroxide/UV. Environ. Sci. Technol. 27 (2), 304-310.

Wang, C.T., Chou, W.L., Chung, M.H., Kuo, Y.M., 2010. COD removal from real dyeing wastewater by electro-Fenton technology using an activated carbon fiber cathode. Desalination 253 (1-3), 129-134.

Wang, H.J., Guo, H., Wu, Q.S., Zhou, G.S., Yi, C.W., 2016. Effect of activated carbon addition on $\mathrm{H}_{2} \mathrm{O}_{2}$ formation and dye decoloration in a pulsed discharge plasma system. Vacuum 128, 99-105.

Zhang, G.W., He, G.H., Xue, W.L., Xu, X.F., Liu, D.N., Xu, Y.H., 2012. Enhanced photocatalytic performance of titania nanotubes modified with sulfuric acid. J. Mol. Catal. A Chem. 363-364, 423-429.

Zhang, M.D., Wei, Y.F., Zhao, K., Mei, R.W., Huang, M., 2011. Glyphosate degradation with industrial wastewater effluent by combined adsorption treatment and advanced oxidation processes. Adv. Mater. Res. 233-235, 369-372.

Zhao, H.Y., Wang, Y.J., Wang, Y.B., Cao, T.C., Zhao, G.H., 2012. Electro-Fenton oxidation of pesticides with a novel $\mathrm{Fe}_{3} \mathrm{O}_{4} @ \mathrm{Fe}_{2} \mathrm{O}_{3}$ /activated carbon aerogel cathode: high activity, wide pH range and catalytic mechanism. Appl. Catal. B Environ. 125, 120-127. 